\title{
Comparison of Grain Zinc and Iron Concentration between Synthetic Hexaploid Wheats and Their Parents
}

\author{
Bo Zhang1,2*, Wenjie Chen ${ }^{1,2^{*}}$, Baolong Liu', ${ }^{1,2}$ Lianquan Zhang ${ }^{3}$, Deyong Zhao, ${ }^{1,2}$, \\ Yuancan Xiao', Dengcai Liu, 1,2,3, Huaigang Zhang1,2\# \\ ${ }^{1}$ Key Laboratory of Adaptation and Evolution of Plateau Biota, Northwest Plateau Institute of Biology, \\ Chinese Academy of Sciences, Xining, China \\ ${ }^{2}$ The Key Laboratory of Crop Molecular Breeding of Qinghai Province, Xining, China \\ ${ }^{3}$ Triticeae Research Institute, Sichuan Agricultural University, Chengdu, China \\ Email: hgzhang@nwipb.ac.cn
}

Received 27 October 2014; revised 23 October 2014; accepted 20 November 2014

Copyright (C) 2014 by authors and Scientific Research Publishing Inc.

This work is licensed under the Creative Commons Attribution International License (CC BY). http://creativecommons.org/licenses/by/4.0/

(c) (i) Open Access

\section{Abstract}

Deficiencies of iron (Fe) and zinc (Zn) in human food afflict a large proportion of the world's population. Wheat is a major food source of minerals. One way to enhance bread wheat's ability to enrich these minerals would be to take advantage of diversity of wild species by creating synthetic hexaploid wheat (SW). In this study, two minerals (Fe and $\mathrm{Zn}$ ) concentrated in the grain of Aegilops tauschii Coss. ( $2 n=2 x=14$, DD), Triticum turgidum L. $(2 n=4 x=28$, AABB), and 33 lines of their corresponding $S W(2 n=2 x=42$, AABBDD) were evaluated. The results showed that Fe concentration was decreased in most of SW lines compared with their parental Aegilops tauschii accessions, while $\mathrm{Zn}$ concentration was greatly increased in most of SW lines compared with their parental Aegilops tauschii accessions. Aegilops tauschii had stronger Fe enrichment than Triticum turgidum while they expressed the same ability for $\mathrm{Zn}$ enrichment. The genotypic variance based on their physiological performance was analyzed. SW lines showed less genotypic variance of Fe and $\mathrm{Zn}$ concentration than Aegilops tauschii. SW lines showed less genotypic variance of Fe concentration than Triticum turgidum $\mathrm{L}$. lines while they had more genotypic variance of $\mathrm{Zn}$ concentration than Triticum turgidum L. lines. Regardless of the fact that the traits expressed in wild relatives of wheat may not predict the traits that will be expressed in SW lines derived from them, production of SW could be a powerful method creating genotypes with enhanced trait expression.

\section{Keywords}

Aegilops tauschii, Allopolyploidzization, Synthetic Wheat, Micronutrient

\footnotetext{
*This two authors contribute equally.

"Corresponding author.
} 


\section{Introduction}

Micronutrient malnutrition is a serious health problem worldwide [1]. Zinc (Zn) and iron (Fe) deficiencies are the most common micronutrient deficiencies in human populations affecting health of over three billion people worldwide [1]. Cereals are an important source of micronutrient minerals for humans. Wheat is a major staple food crop and its nutritional quality have a significant impact on human health and well-being, especially in developing countries [2] [3]. Breeding of wheat cultivars with increased micronutrient concentration is a low-cost and sustainable strategy for alleviating micronutrient malnutrition. However, common wheat cultivars usually have low grain Fe and Zn contents [2] [4] [5], with a narrow genotypic variations [6]-[10].

Common wheat is an allohexaploid species that originated from natural hybridization between tetraploid wheat (Triticum turgidum L.) and Aegilops tauschii Cosson [11] [12]. Ae. tauschii, the D-genome donor of common wheat, has a very wide geographic distribution extending westwards to Turkey and eastwards to Afghanistan and China [13]-[15] and shows abundant genetic variations [16]-[18]. Since only a few Ae. tauschii accessions was involved in the origin of common wheat, a lot of genetic diversities in this species are not represented in common wheat population. Ae. tauschii provides important genetic resources for the common wheat improvement of Fe and Zn concentrations [7]-[10] [19].

Artificially synthetic hexaploid wheat (SHW) between T. turgidum and Ae. tauschii has been used as a bridge for transfer the gene from Ae. tauschii into common wheat. In the present study, Fe and $\mathrm{Zn}$ concentration of Ae. tauschii, T. turgidum, and their corresponding synthesized lines were compared to investigate their expression in hexaploid level and to choose synthetic hexaploid for nutritional quality improvement of common wheat.

\section{Materials and Method}

\subsection{Plant Materials}

Thirty-three synthetic hexaploid wheat and their parents, including 13 Ae. tauchii accessions and 23 T. turgidun lines, were produced by Dr. Dengcai Liu (Table 1). These Ae. tauchi I and T. turgidun have diverse geographic origins and belongs to different subspecies. Synthesized hexaploid wheat lines were produced through spontaneous chromosome doubling via union of unreduced gametes [20]. All these materails were grown at 1 row $1 \mathrm{~m}$ length plot in irrigated field trials with 2 replications at Wen Jiang of Triticeae Research Institute of Sichuan Agricultural University in the 2009-2010 crop season.

\subsection{Chemical Analysis}

Grain samples were analyzed for Fe and Zn concentrations by atomic absorption spectrometry according to Orhan et al. [21]. The grain samples were washed with distillated water, a $0.1 \mathrm{~mol} \cdot \mathrm{L}^{-1} \mathrm{HCl}$ solution and deionized water. After being dried in a laboratory oven at $65^{\circ} \mathrm{C}$, the dry matter was quantified, and then submitted to grinding. Fe and $\mathrm{Zn}$ were quantified in an extract obtained by nitro-perchloric digestion and their content was determined by conventional atomic absorption spectrometry run with an air-acetylene flame.

\subsection{Statistical Analysis}

Data were analyzed using analysis of variance (ANOVA). The correlations among the physiological traits were estimated based on Pearson correlation coefficient values.

\section{Results}

\subsection{Distribution of Fe and Zn Contents in Aegilops tauschii, Triticum turgidum Accessions, and SHW Lines}

For the Fe element, of $33 \mathrm{SW}$ lines, 82\% displayed the concentration of between their corresponding two parents, $12 \%$ displayed the concentration of higher than their corresponding two parents, while only $6 \%$ of them displayed concentrations lower than their corresponding parents. For the Zn element, of $33 \mathrm{SW}$ lines, 82\% displayed the concentration higher than their corresponding parents, $15 \%$ of them displayed concentration between their corresponding parents, 3\% of them showed decreased Zn concentration after allopolyploidization compared with corresponding parents (Tables 2-4, Figure 1 and Figure 2). 
Table 1. T. turgidum genotypes and Ae. tauschii accessions used to develop synthetic hexaploids.

\begin{tabular}{|c|c|}
\hline SHW & T. turgidum Ae. tauschii \\
\hline Syn-SAU-6 & ssp. durum Langdon x ssp. tauschii AS65 (Former Soviet Union) \\
\hline Syn-SAU-8 & ssp. durum Langdon x ssp. strangulata AS2386 (Iran) \\
\hline Syn-SAU-11 & ssp. durum Langdon x ssp. strangulata AS2407 \\
\hline Syn-SAU-13 & ssp. turgidum AS2255 (China) x ssp. tauschii AS2395 \\
\hline Syn-SAU-14 & ssp. turgidum AS2255 (China) x ssp. strangulata AS2393 \\
\hline Syn-SAU-19 & ssp. turgidum AS2236-2 (Sichuan, China) x ssp. tauschii AS82 (Henan, China) \\
\hline Syn-SAU-21 & ssp. turgidum AS2239 (Sichuan, China) x ssp. tauschii AS2395 \\
\hline Syn-SAU-24 & ssp. turgidum AS2291 (Shannxi, China) x ssp. Strangulate AS2404 \\
\hline Syn-SAU-25 & ssp. dicoccoides AS285 (Germany) x ssp. strangulata AS66 (Former Soviet Union) \\
\hline Syn-SAU-26 & ssp. dicoccoides AS285 (Germany) x ssp. strangulataAS2386 (Iran) \\
\hline Syn-SAU-27 & ssp. dicoccoides AS285 (Germany) x ssp. strangulata AS2404 \\
\hline Syn-SAU-28 & ssp. dicoccoides AS285 (Germany) x ssp. strangulata AS2405 \\
\hline Syn-SAU-29 & ssp. dicoccoides AS286 (France) x ssp. strangulata AS66 (Former Soviet Union) \\
\hline Syn-SAU-30 & ssp. dicoccoides AS286 (France) x ssp. strangulate AS2386 (Iran) \\
\hline Syn-SAU-31 & ssp. dicoccoides AS286 (France) x ssp. strangulata AS2399 \\
\hline Syn-SAU-33 & ssp. dicoccoides AS286 (France) x ssp. strangulata AS2407 \\
\hline Syn-SAU-34 & ssp. dicoccon PI94614 (Ukraine) x ssp. strangulata AS2405 \\
\hline Syn-SAU-35 & ssp. dicoccon PI94627 (Asia Minor) x ssp. strangulata AS2386 (Iran) \\
\hline Syn-SAU-37 & ssp. dicoccon PI94655 (Bulgaria) x ssp. strangulata AS2404 \\
\hline Syn-SAU-38 & ssp. dicoccon PI94655 (Bulgaria) x ssp. strangulata AS2407 \\
\hline Syn-SAU-39 & ssp. dicoccon PI94666 (Dagestan) x ssp. strangulata AS2407 \\
\hline Syn-SAU-42 & ssp. dicoccon PI94675 (Georgia) x ssp. strangulata AS2405 \\
\hline Syn-SAU-43 & ssp. dicoccon PI113961 (Georgia) x ssp. strangulata AS2404 \\
\hline Syn-SAU-45 & ssp. dicoccon PI154582 (Taiwan) x ssp. tauschii AS2395 \\
\hline Syn-SAU-51 & ssp. dicoccon PI350001 (Yugoslavia) x ssp. strangulata AS2405 \\
\hline Syn-SAU-54 & ssp. dicoccon PI352335 (USA) x ssp. strangulata AS2386 (Iran) \\
\hline Syn-SAU-55 & ssp. dicoccon PI352358 (France) x ssp. tauschii AS65 (Former Soviet Union) \\
\hline Syn-SAU-60 & ssp. dicoccon PI355465 (Namur, Belgium) x ssp. strangulate AS2405 \\
\hline Syn-SAU-66 & ssp. dicoccon PI355527 (Balkans) x ssp. strangulata AS2399 \\
\hline Syn-SAU-69 & ssp. dicoccon PI415152 (Israel) x ssp. tauschii AS60 \\
\hline Syn-SAU-80 & ssp. turgidum AS2296 (Sichuan, China) x ssp. Strangulate AS2388 (Iran) \\
\hline Syn-SAU-86 & ssp. turgidum AS2313 (Sichuan, China) x ssp. Strangulate AS2388 (Iran) \\
\hline Syn-SAU-93 & ssp. turgidum AS2382 (Shannxi, China) x ssp. strangulate AS2388 (Iran) \\
\hline
\end{tabular}

Table 2. Distribution of 33 SW lines according to Fe, Zn, and Se contents compared with their parents.

\begin{tabular}{|c|c|c|c|c|c|}
\hline \multicolumn{3}{|c|}{$\mathrm{Fe}(\%)$} & \multicolumn{3}{|c|}{ Zn (\%) } \\
\hline$>$ parents & between parents & $<$ parents & $>$ parents & between parents & $<$ parents \\
\hline $12 \%$ & 6 & $12 \%$ & $82 \%$ & $15 \%$ & $3 \%$ \\
\hline
\end{tabular}

Table 3. Variation in morphological traits in synthetics and corresponding Aegilops tauschii parental accessions.

\begin{tabular}{cccccccccc}
\hline & \multicolumn{7}{c}{ Ythetic Wheat Lines Accessions Aegilops tauschii } \\
\hline Characteristic & Mean \pm SD & Max & Min & $\begin{array}{c}\text { Coefficient } \\
\text { of variation }\end{array}$ & Mean \pm SD & Max & $\begin{array}{c}\text { Min } \\
\text { Coefficient } \\
\text { of variation }{ }^{1}\end{array} \begin{array}{c}\text { correlation } \\
\text { of value }\left(r^{2}\right)\end{array}$ \\
\hline Fe (mg/kg) & $48.80 \pm 11.26$ & 70.36 & 27.09 & 0.23 & $91.59 \pm 37.06$ & 84.70 & 27.29 & 0.41 & 0.031 \\
Zn (mg/kg) & $149.24 \pm 50.13$ & 268.96 & 57.51 & 0.33 & $70.88 \pm 29.40$ & 113.83 & 10.29 & 0.42 \\
\hline
\end{tabular}

${ }^{1}$ Coefficients of variation are based on SD/Mean. 


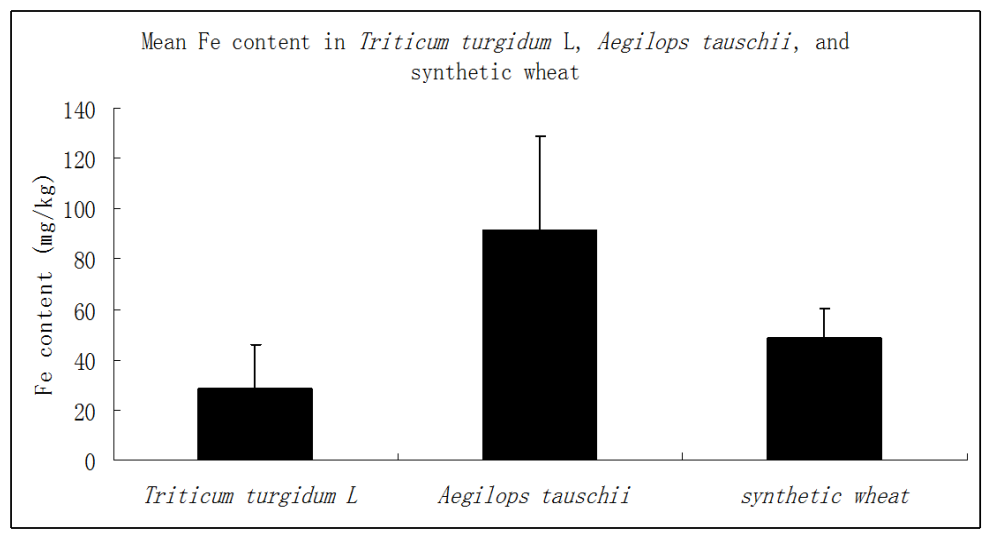

Figure 1. Mean concentration of grain Fe in 33 Triticum turgidum L., Aegilops tauschii accessions and their corresponding SW lines.

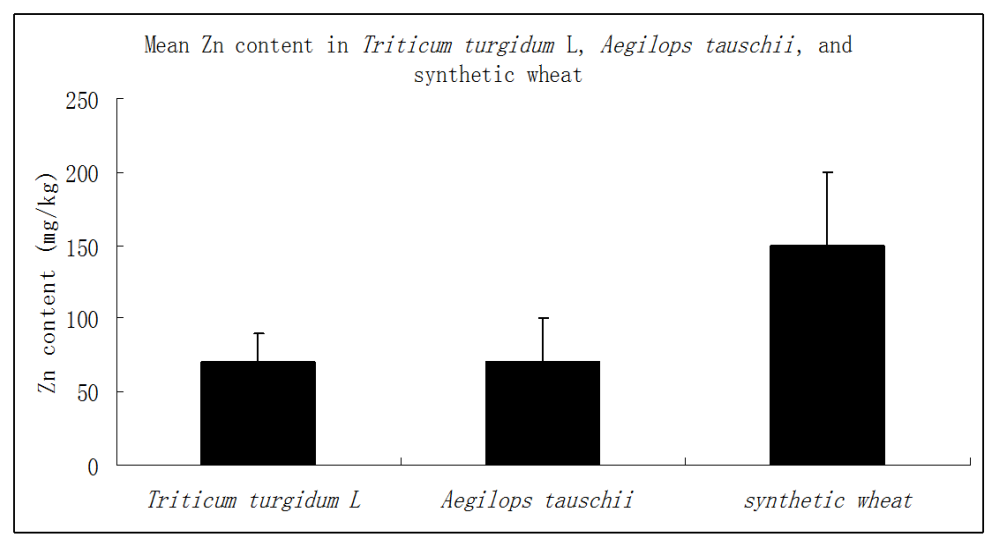

Figure 2. Mean concentration of grain $\mathrm{Zn}$ in 33 Triticum turgidum L., Aegilops tauschii accessions and their corresponding SW lines.

Table 4. Variation in morphological traits in synthetics and corresponding Triticum turgidum L. parental accessions.

\begin{tabular}{|c|c|c|c|c|c|c|c|c|c|}
\hline \multicolumn{5}{|c|}{ Ythetic Wheat Lines Accessions } & \multicolumn{5}{|c|}{ Triticum turgidum L. } \\
\hline Characteristic & Mean \pm SD & $\operatorname{Max}$ & Min & $\begin{array}{l}\text { Coefficient } \\
\text { of variation }\end{array}$ & Mean \pm SD & Max & Min & $\begin{array}{l}\text { Coefficient } \\
\text { of variation }{ }^{1}\end{array}$ & $\begin{array}{l}\text { correlation } \\
\text { of value }\left(r^{2}\right)\end{array}$ \\
\hline $\mathrm{Fe}(\mathrm{mg} / \mathrm{kg})$ & $48.80 \pm 11.26$ & 70.36 & 27.09 & 0.23 & $28.60 \pm 17.31$ & 86.15 & 3.00 & 0.61 & 0.056 \\
\hline Zn (mg/kg) & $149.24 \pm 50.13$ & 268.96 & 57.51 & 0.33 & $70.19 \pm 20.02$ & 103.77 & 39.86 & 0.28 & 0 \\
\hline
\end{tabular}

${ }^{1}$ Coefficients of variation are based on SD/Mean.

The mean grain Fe concentration in Aegilops tauschii was significantly higher than that in Triticum turgidum L. The mean grain Zn concentration was in the same level in Aegilops tauschii and Triticum turgidum (Table 3 and Table 4). The mean concentration of grain Fe in $33 \mathrm{SW}$ lines decreased by $66 \%$ compared with the corresponding diploid parent Aegilops tauschii (Table 3; Figure 1). While the mean concentration of grain Zn in $33 \mathrm{SW}$ lines increased by 113\% compared with the corresponding diploid parent Aegilops tauschii (Table 3, Figure 2).

\subsection{The SW Lines Showed Lower Variance of Fe and Zn Concentration}

The genotypic variance of the three group lines was analyzed based on their physiological performance, using the coefficient of variation as a parameter. SW lines showed less genotypic variance than Aegilops tauschii in Fe, Zn, and Se concentration. SW lines showed less genotypic variance than Triticum turgidum L. lines in Fe and Se concentration while they had more genotypic variance than Triticum turgidum L. lines in $\mathrm{Zn}$ concentration (Table 3 and Table 4; Figure 3, Figure 4). 


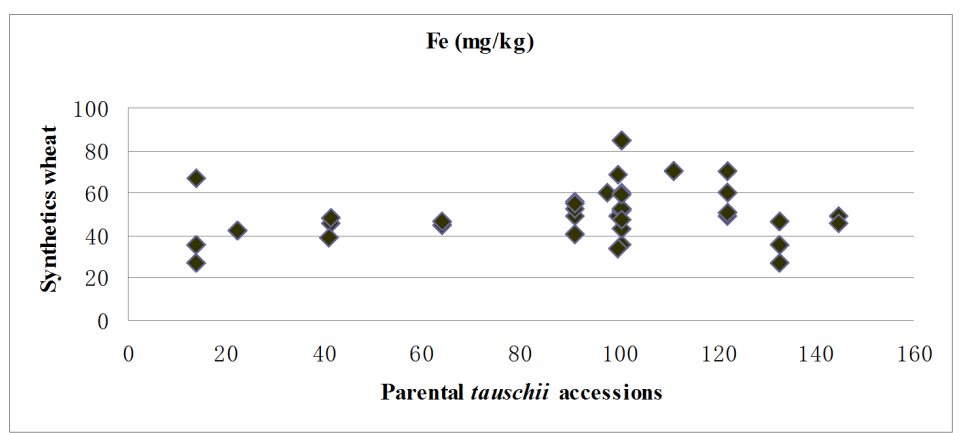

Figure 3. Comparisons of variability Fe concentration in parental Aegilops tauschii accessions and synthetic hexaploids.

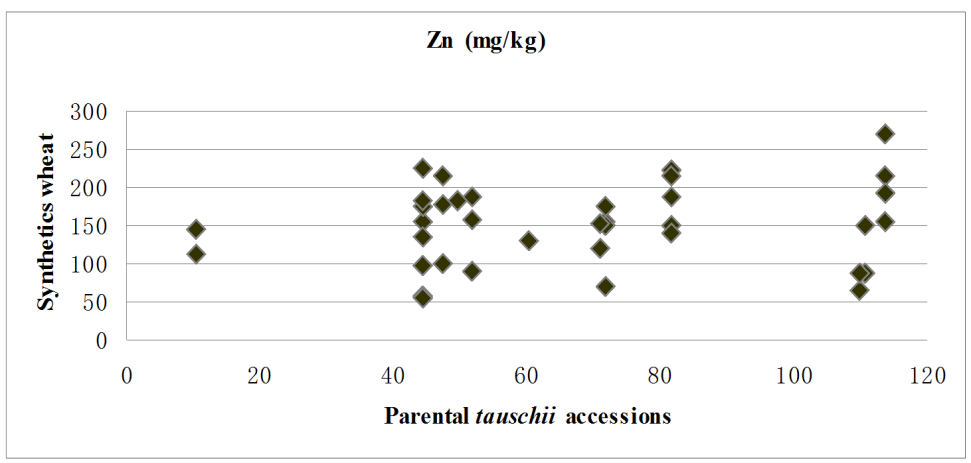

Figure 4. Comparisons of variability Zn concentration in parental Aegilops tauschii accessions and synthetic hexaploids.

\subsection{Correlation of Traits of Ae. tauschii and Triticum turgidum L. Accessions with Those of Their Corresponding SW Lines}

No physiological traits (Fe and Zn concentration) of the SW lines were significantly correlated with the corresponding traits of their parental Ae. tauschii and Triticum turgidum L. lines (Table 3 and Table 4).

\section{Discussion}

Successful expression of useful characters of wild wheat relatives in synthetic hexaploid level is a key step for common wheat improvement. The narrow genetic variation in Fe and $\mathrm{Zn}$ concentrations of wheat has limited the breeding of wheat to enhance the Fe and $\mathrm{Zn}$ concentrations in grain. Wheat relatives show wide genetic variation in these characters [22] [23]. In this study, comparative studies of two mineral traits among and between the synthetics and their parental Ae. tauschii and Triticum turgidum L. accessions were conducted. The results showed that Ae. tauschii had wider variations of Fe concentration than SW lines and SW lines had wider variations of $\mathrm{Zn}$ concentration than Ae. tauschii accessions. The variations observed at the diploid genome level were not necessarily reflected in the synthetics (Table 2, Figures 1-4). Significant variation in most of the morphological and physiological characteristics was measured in the Ae. tauschii accessions [18] [24].

Meanwhile, Aegilops tauschii had stronger Fe enrichment ability than Triticum turgidum while they had the same ability for Zn enrichment. The average concentrations of grain Fe in SW lines were $50 \%$ lower than $A e$. tauschii, respectively (Figure 1), indicating that allopolyploidization reduced the expression of Fe enrichment characters in Ae. tauschii. Interestingly, the variation of $\mathrm{Zn}$ concentration was wider in SW lines compared with their corresponding tetraploid and diploid parental lines. Zn concentration was significantly increased after allopolyploidization in most of the combinations. In $33 \mathrm{SW}$ lines, 82\% of them had higher Zn concentration than their corresponding tetraploid and diploid parental lines (Table 2), indicating that grain Zn accumulation was significantly stimulated by allopolyploidization. Previous research work indicated that alien chromosome addition wheat lines derived from 6 species of Aegilops tauschii showed increased grain $\mathrm{Zn}$ concentration of be- 
tween 50\% and 248\% compared with the recipient cultivar, Chinese Spring [25]. This is consistent with our result of Zn.

Repression of D genome variation has been commonly observed for most morphological traits in synthetic hexaploid wheats [26] [27], indicating that the expression of D genome variation was masked. Allopolyploidization is often accompanied by genetic and epigenetic modification of the genome as previously observed in synthetic polyploids of wheat and Arabidopsis [25] [28]-[31]. In the present study, the changes of high Fe concentration character and low Zn concentration of Aetauschhi by allopolyploidization should be the results of genome interaction between $\mathrm{A}, \mathrm{B}$, and $\mathrm{D}$ genome because our recent data from similar SW lines indicated that allohexaploidization of wheat did not increase the SSR mutation rate [32].

Regardless of the fact that the traits expressed in wild relatives of wheat may not predict the traits that will be expressed in SW lines derived from them, production of SW could be a powerful method creating genotypes with enhanced trait expression.

\section{Acknowledgements}

The research was financially supported by National Natural Science Foundation of China (31101140), Science and Technology Planning Project of Qinghai Province, China (2011-Z-716; 2013-Z-942Q), "The Dawn of West China” Talent Training Program of CAS and the Program of West Action of CAS (KZCX2-XB3-05).

\section{References}

[1] Welch, R.M. and Graham, R.D. (2004) Breeding for Micronutrients in Staple Food Crops from a Human Nutrition Perspective. Journal of Experimental Botany, 55, 353-364. http://dx.doi.org/10.1093/jxb/erh064

[2] Cakmak, I. (2008) Enrichment of Cereal Grain with Zinc: Agronomic or Genetic Biofortification? Plant Soil, 302, 1-17. http://dx.doi.org/10.1007/s11104-007-9466-3

[3] FAO (2006) The State of Food Insecurity in the World 2006. Statistics Division, United Nations, Rome. http://www.fao.org/docrep/009/a0750e/a0750e00.HTM

[4] Joshi, A.K., Crossa, J., Arun, B., Chand, R., Trethowan, R., Vargas, M. and Ortiz-Monasterio, I. (2010) Genotype $\times$ Environment Interaction Forzinc and Iron Concentration of Wheat Grain in Eastern Gangetic Plains of India. Field Crops Research, 116, 268-277. http://dx.doi.org/10.1016/j.fcr.2010.01.004

[5] Morgounov, A., Gómez-Becerra, H.F., Abugalieva, A., Dzhunusova, M., Yessimbekova, M., Muminjanov, H., Zelenskiy, Y., Ozturk, L. and Cakmak, I. (2007) Iron and Zinc Grain Density in Common Wheat Grown in Central Asia. Euphytica, 155, 193-203. http://dx.doi.org/10.1007/s10681-006-9321-2

[6] Zhao, F.J., Su, Y.H., Dunham, S.J., Rakszegi, M., Bedo, Z., McGrath, S.P. and Shewry, P.R. (2009) Variation in Mineral Micronutrient Concentrations in Grain of Wheat Lines of Diverse Origin. Journal of Cereal Science, 49, $290-295$. http://dx.doi.org/10.1016/j.jcs.2008.11.007

[7] Cakmak, I., Ozkan, H., Braun, H.J., Welch, R.M. and Romheld, V. (2000) Zinc and Iron Concentrations in Seeds of Wild, Primitive and Modern Wheats. Food and Nutrition Bulletin, 21, 401-403.

[8] Monasterio, I. and Graham, R.D. (2000) Breeding for Trace Minerals in Wheat. Food and Nutrition Bulletin, 21, 392396.

[9] Chhuneja, P., Dhaliwal, H.S., Bains, N.S. and Singh, K. (2006) Aegilopskotschyi and Aegilops tauschii Are the Sources for High Grain Iron and Zinc. Plant Breed, 125, 529-531. http://dx.doi.org/10.1111/j.1439-0523.2006.01223.x

[10] Rawat, N., Tiwari, V.K., Singh, N., Randhawa, G.S., Singh, K., Chhuneja, P. and Dhaliwal, H.S. (2008) Evaluation and Tilization of Aegilops and Wild Triticum Species for Enhancing Iron and Zinc Content in Wheat. Genetic Resources and Crop Evolution, 56, 53-64. http://dx.doi.org/10.1007/s10722-008-9344-8

[11] Kihara, H. (1944) Discovery of the DD-Analyser, One of the Ancestors of Triticum vulgare (abstr) (in Japanese). Agriculture and Horticulture, 19, 889-890.

[12] McFadden, E.S. and Sears, E.R. (1944) The Artificial Synthesis of Triticum spelta. Records of the Genetics Society of America, 13, 26-27.

[13] Kihara, H., Yamashita, K. and Tanaka, M. (1965) Morphological, Physiological, Genetic and Cytological Studies in Aegilops and Triticum Collected from Pakistan, Afghanistan and Iran. In: Yamashita, K., Ed., Results of the Kyoto University Scientific Expedition to the Karakoram and Hindukush, Kyoto University, Kyoto, 1-118.

[14] Yen, C., Yang, J.L. and Liu, X.D. (1983) The Distribution of Aegilops tauschii Cosson in China and with Reference to the Origin of the Chinese Common Wheat. Proceedings of the 6th International Wheat Genetics Symposium, Kyoto, 28 
November-3 December 1983, 55-58.

[15] Jakaska, V. (1995) Isoenzymes in the Evaluation of Germplasm Diversity in Wild Diploid Relatives of Cultivated Wheat. In: Damania, A.B., Ed., Biodiversity and Wheat Improvement, ICARDA, Wiley-Sayce Publ., London, 247-257.

[16] Dudnikov, A.J. and Goncharov, N.P. (1993) Allozyme Variation in Aegilops squarrosa. Hereditas, 119, 117-122. http://dx.doi.org/10.1111/j.1601-5223.1993.00117.x

[17] Dvorak, J., Luo, M.C., Yang, Z.L. and Zhang, H.B. (1998) The Structure of the Aegilops tauschii Genepool and the Evolution of Hexaploid Wheat. Theoretical and Applied Genetics, 97, 657-670. http://dx.doi.org/10.1007/s001220050942

[18] Dudnikov, A.J. and Kawahara, T. (2006) Aegilops tauschii: Genetic Variation in Iran. Genetic Resources and Crop Evolution, 53, 579-586. http://dx.doi.org/10.1007/s10722-004-2681-3

[19] Wang, S.W., Lina, Y., Hiroyuki, T., Kiyoshi, T. and Hisashi, T. (2011) Wheat-Aegilops Chromosome Addition Lines Showing High Iron and Zinc Contents in Grains. Breeding Science, 61, 189-195. http://dx.doi.org/10.1270/jsbbs.61.189

[20] Zhang, L., Zhang, L., Luo, J., Chen, W., Hao, M., Liu, B., Yan, Z., Zhang, B., Zhang, H., Zheng, Y., Liu, D. and Yen, Y. (2011) Synthesizing Double Haploid Hexaploid Wheat Populations Based on a Spontaneous Alloploidization Process. Journal of Genetics and Genomics, 38, 89-94. http://dx.doi.org/10.1016/j.jcg.2011.01.004

[21] Orhan, A., Ali, R.T. and Ziya, K. (2008) Flame Atomic Absorption Spectrometric Determination of Iron, Magnesium, Strontium and Zinc in Human Teeth Using La + K Mixture. Acta Chimica Slovenica, 55, 462-467.

[22] Cakmak, I., Torun, A., Özkan, H., Millet, E., Feldman, M., Fahima, T., Korol, A.B., Nevo, E. and Braun, H.J. (2004) Triticum dicoccoides: An Important Genetic Resource for Increasing Zinc and Iron Concentration in Modern Cultivated Wheat. Soil Science and Plant Nutrition, 50, 1047-1054. http://dx.doi.org/10.1080/00380768.2004.10408573

[23] Tiwari, V.K., Rawat, N., Neelam, K., Kumar, S., Randhawa, G.S. and Dhaliwal, H.S. (2010) Substitution of 2S and 7U Chromosomes of Aegilops kotschyi in Wheat Enhances Grain Iron and Zinc Concentration. Theoretical and Applied Genetics, 121, 259-269. http://dx.doi.org/10.1007/s00122-010-1307-8

[24] Sohail, Q., Inoue, T., Tanaka, H., Eltayeb, A.E., Matsuoka, Y. and Tsujimoto, H. (2011) Applicability of Aegilops tauschii Drought Tolerance Traits to Breeding of Hexaploid Wheat. Breeding Science, 61, 347-357. http://dx.doi.org/10.1270/jsbbs.61.347

[25] Wang, J., Tian, L., Madlung, A., Lee, H.-S., Chen, M., Lee, J.J., Watson, B., Kagochi, T., Comai, L. and Chen, Z.J. (2004) Stochastic and Epigenetic Changes of Gene Expression in Arabidopsis Polyploids. Genetics, 167, 1961-1973. http://dx.doi.org/10.1534/genetics.104.027896

[26] Takumi, S., Naka, Y., Morihiro, H. and Matsuoka, Y. (2009) Expression of Morphological and Flowering Time Variation through Allopolyploidization: An Empirical Study with 27 Wheat Synthetics and Their Parental Aegilops tauschii Accessions. Plant Breed, 128, 585-590. http://dx.doi.org/10.1111/j.1439-0523.2009.01630.X

[27] Fujwara, Y., Shimada, S., Takumi, S. and Mura, K. (2010) Differential Effects of Aegilops tauschii Genotypes on Maturing-Time in Synthetic Hexaploid Wheats. Breeding Science, 60, 286-292. http://dx.doi.org/10.1270/jsbbs.60.286

[28] Ozkan, H., Levy, A.A. and Feldman, M. (2001) Allopolyploidy Induced Rapid Genome Evolution in the Wheat Aegilops triticum) Group. Plant Cell, 13, 1735-1747. http://dx.doi.org/10.1105/tpc.13.8.1735

[29] Shaked, H., Kashkush, K., Ozkan, H., Feldman, M. and Levy, A.A. (2001) Sequence Elimination and Cytosine Methylation Are Rapid and Reproducible Responses of the Genome to Wide Hybridization and Allopolyploidy in Wheat. Plant Cell, 13, 1749-1759. http://dx.doi.org/10.1105/tpc.13.8.1749

[30] Madlung, A., Madlung, A., Masuelli, R.W., Watson, B., Reynolds, S.H., Davison, J. and Comai, L. (2002) Remodeling of DNA Methylation and Phenotypic and Transcriptional Changes in Synthetic Arabidopsis Allotetraploids. Plant Physiology, 129, 733-746. http://dx.doi.org/10.1104/pp.003095

[31] Khasdan, V., Yaakov, B., Kraitshtein, Z. and Kashkush, K. (2010) Developmental Timing of DNA Elimination Following Allopolyploidization in Wheat. Genetics, 185, 387-390. http://dx.doi.org/10.1534/genetics.110.116178

[32] Luo, J., Hao, M., Zhang, L., Chen, J., Zhang, L., Yuan, Z., Yan, Z., Zheng, Y., Zhang, H., Yen, Y. and Liu, D. (2012) Microsatellite Mutation Rate during Allohexaploidization of Newly Resynthesized Wheat. International Journal of Molecular Sciences, 13, 12533-12543. http://dx.doi.org/10.3390/ijms131012533 
Scientific Research Publishing (SCIRP) is one of the largest Open Access journal publishers. It is currently publishing more than 200 open access, online, peer-reviewed journals covering a wide range of academic disciplines. SCIRP serves the worldwide academic communities and contributes to the progress and application of science with its publication.

Other selected journals from SCIRP are listed as below. Submit your manuscript to us via either submit@scirp.org or Online Submission Portal.
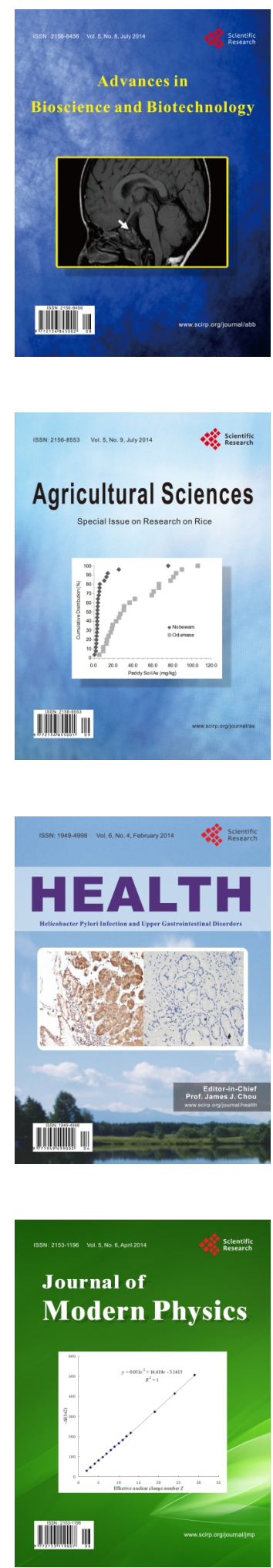
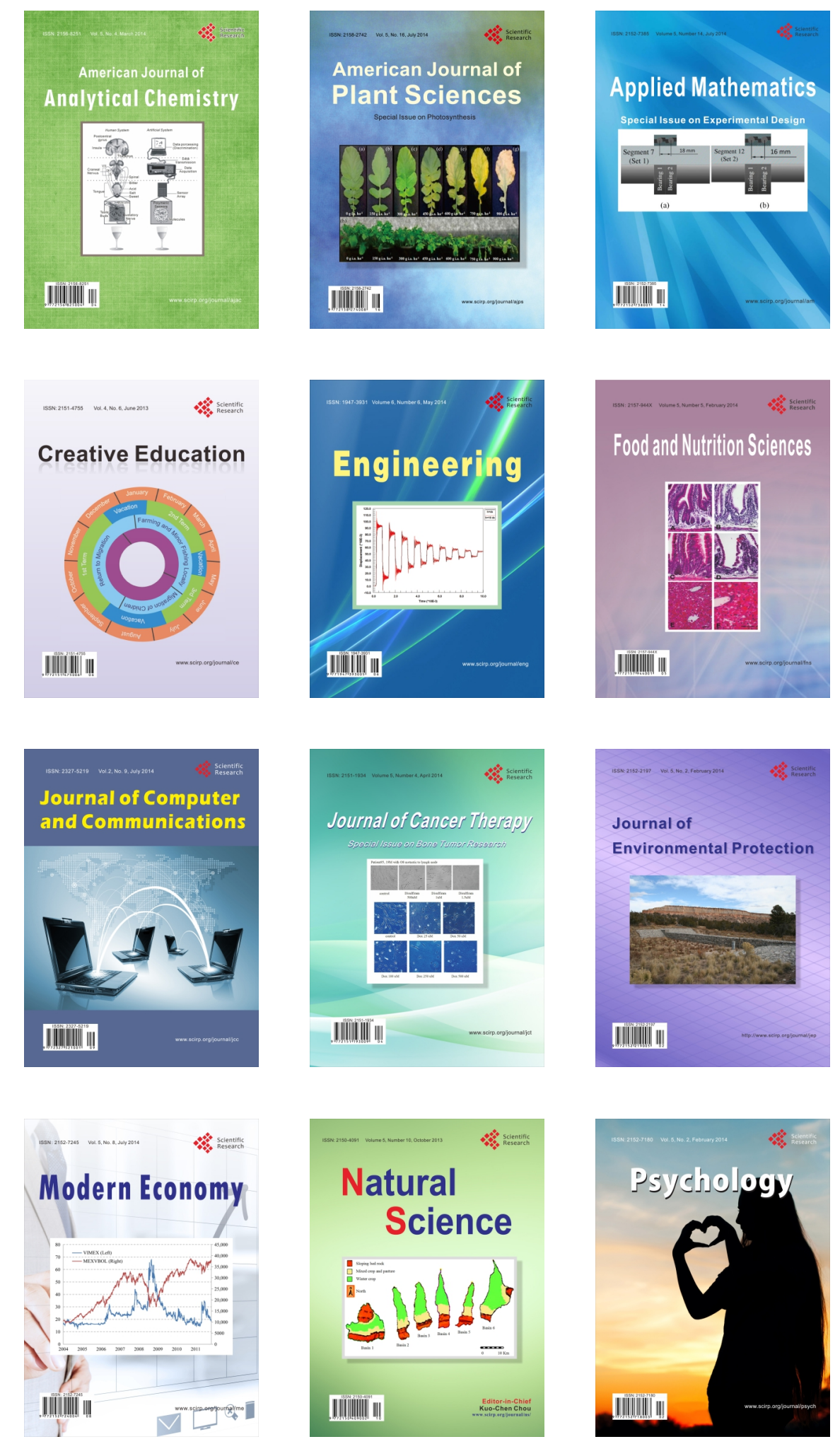